\title{
Comparison of model materials for investment casting made by rapid prototyping
}

\author{
Marko Bednárik * and Juraj Beniak \\ Slovak University of Technology in Bratislava, Faculty of Mechanical Engineering, Nam. Slobody 17, 81231 Bratislava, \\ Slovak Republic.
}

Global Journal of Engineering and Technology Advances, 2022, 10(01), 075-086

Publication history: Received on 24 November 2021; revised on 12 January 2022; accepted on 14 January 2022

Article DOI: https://doi.org/10.30574/gjeta.2022.10.1.0177

\begin{abstract}
This paper deals with a comparison of different materials to produce models for investment casting technology using additive manufacturing methods. The work is focused on three materials for FDM type printers, as well as two resins for SLA printing devices. To create a comprehensive image of each filament the materials are presented in terms of technology, the need for additional post processing, as well as physical and mechanical properties for each product.
\end{abstract}

Keywords: Additive technologies; Wax like filaments; Investment casting; FDM; SLA

\section{Introduction}

The manufacturing technique called investment casting using a wax model is a common centuries-old process. This type of casting production consists in making a wax model that is coated with a ceramic material. The wax is then melted from the ceramic shell and metal required by the customer is poured into the cavity, forming the final cast. [1]

Making wax models is the first and one of the most expensive tasks in the whole process. Metal molds made of lowmelting alloys are commonly used for this step. These molds are mainly made by milling into a block of material in which the negative of the desired product is formed. The parts processed in this way are not only time-consuming and technologically demanding for production, but they also represent a great financial burden for the customer, especially if the design of a part is not yet finalized. The most used types of wax are paraffin and microcrystalline waxes. [2] [3]

After the mold for wax models is made, a production series is manufactured. These wax pieces are then attached to wax trees containing a series of models. The wax tree is then alternately soaked in a ceramic fluid and covered with zircon sand. Between steps, the shell is dried to gain strength and hardness. After the coating and drying process is completed, the wax is melted from the shell. This is achieved in specialized devices to ensure the Flash melt effect. This process is extremely important because it is necessary to heat shock the top layer of wax that touches the shell before the models overheat.

If the model and the tree were overheated at once in full volume, the wax would expand due to the change in volume during the change of state, which would result in the shell bursting. The melting of the top layer will provide space for the wax residue to expand during melting. After this step, the shell is ready for annealing and subsequent casting. Almost any material can be applied to ceramic shells, which ensures a wide range of uses for this production process. After casting, the ceramic shell is broken and the castings themselves are separated from the inlet channel and further processed. [1] [3] [4]

\footnotetext{
${ }^{*}$ Corresponding author: Marko Bednárik

Slovak University of Technology in Bratislava, Faculty of Mechanical Engineering, Nam. Slobody 17, 81231 Bratislava, Slovak Republic.
} 
The investment casting technology is known for its precise production of so-called near net shape castings, which require a minimum of finishing. The castings have excellent geometric accuracy and sufficient surface roughness tolerance for direct use in final products. The whole process is illustrated in Figure 1. [5]

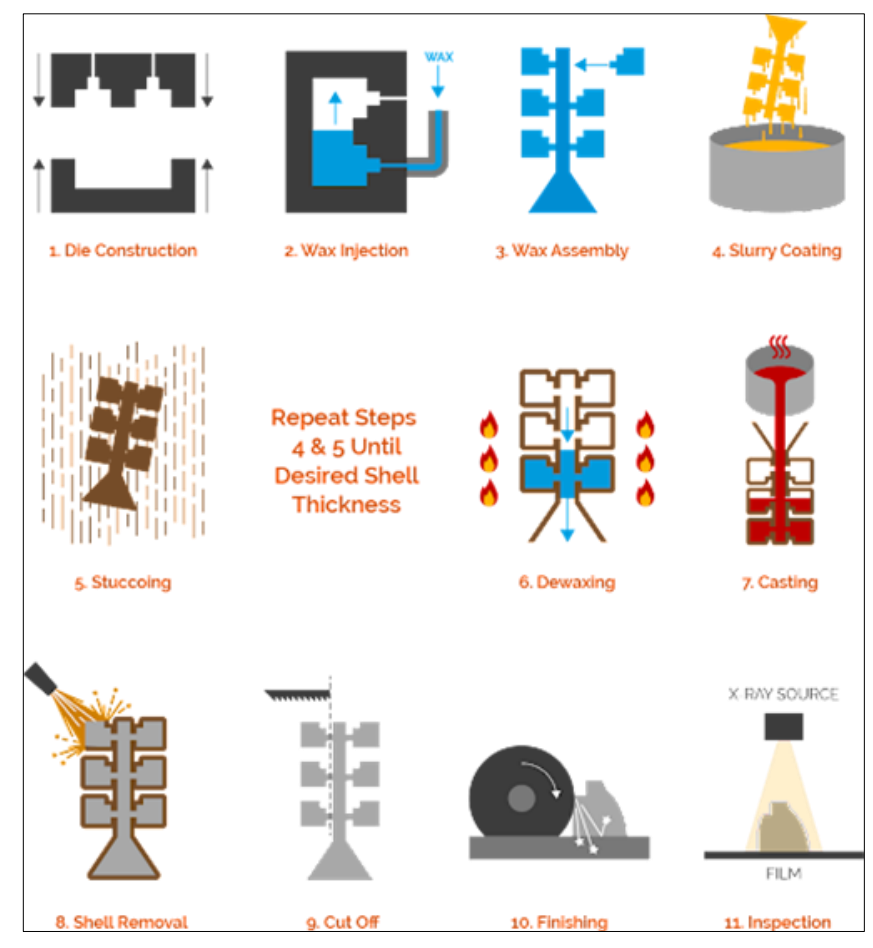

Figure 1 Illustration of investment casting technology [5]

A key point of research in improving the efficiency of investment casting technology is to make wax models faster and cheaper than it is possible with conventional methods. As already mentioned, conventional milled molds represent a significant financial burden for the project and the production of the part itself. Neither do such molds provide much opportunity to modify the shape of the part after the mold has been made. For many customers, it is very important to test the part before it goes into series production, to establish, in terms of the expected number of pieces, whether it is worth investing in series production. For these purposes, it is ideal to apply additive manufacturing technology. These processes are used in production areas such as rapid prototyping and therefore represent a suitable combination of production speed and low cos. These factors allow realization of manufacturing samples for investment casting technology, or even the implementation of small series production possible without overpricing the process. [1] [4]

The reduction in price compared to conventional milled molds is due to the absence of the need to produce any molds for creating wax models. Using additive technologies, individual wax parts are created directly in 3D printers. As recent studies show ( [6] [7]) the main reason why many foundries try to implement additive technologies into their processes is the reduction of production time of the first prototypes including the time spent manufacturing milled molds. [8] [9]

The possibility of producing shape-demanding models is also one of the benefits of using additive technologies to produce wax models. This effect can be applied especially to very complex components for which the production of a classic mold for wax injection molding would not be financially acceptable or even impossible to manufacture. Thanks to the additive technology, it is possible to experiment with the typological optimization of the part directly when prototyping the part without the need for production and mold modification in these experiments. This study will also deal with the advantages and problems that accompany modern additive technologies in the field of precision casting for conventional as well as "rapid prototyping" production.

When applying the production methods of rapid prototyping in the process of investment casting, there are problems caused by individual production techniques or materials that are used in these processes. As clarified by the EARP group project, which focused on examining some of the main types of prototyping for investment casting. The focus was mainly on two production processes, which are "Selective laser sintering (SLS)" and "Fused deposit modeling (FDM)". Both processes can create models directly from wax material that can be directly applied to the investment casting process. 
At the same time, they also allow the use of wax-like materials. However, one of the main problems with the use of wax substitutes is the fact that there is a high probability of shell damage when melting models.

If the process is carried out in a steam machine such as an autoclave, expansion, or incompatibility of substitution materials from 3D printing can cause expansion problems, or on the other hand if the temperature in the autoclaves is insufficient, this process can lead to imperfect firing of models and thus devaluation of the subsequent castings batch.

Many companies are trying to develop a universal material that would not affect serial processes in foundries and could be implemented in production side by side with classic wax models. [6] [7]

\section{Benefits of rapid prototyping technologies}

The basic benefit for the customer is the financial savings associated with the production of the mold as well as the time that such preparation would take before the actual production of parts. The prices of the molds for the wax injection molding machine, depending on the complexity of the part, range from $1,000 €$ to $€ 50,000$. Also, the production time can be up to 16 weeks. [6] [8]

For any part that has not undergone physical testing, there is a high presumption of design changes during the implementation of the part into production. When using prototyping technologies, it is not necessary to worry about changes in design even during the first production batches, as production does not require a milled form and therefore any modification is possible. The mold for serial production is made only after the technical changes on the part have been completed. [8]

Another problem for which it is ideal to use models made by 3D printing technology is the sprue technology on the casting itself. For more demanding models, the correct choice of sprue positioning and venting elements may be ambiguous. If the technology is poorly designed, it can lead to several foundry defects during production, such as cracks, hot tears, or unsatisfactory metallographic structure of the casting. Thanks to the use of models made using rapid prototyping, it is possible to verify the individual variants of the technology directly in practice and, based on real results, choose the optimal procedure according to which the milled mold will be made. These first designs also allow the factory to obtain information about the part's ability to bind the coating material and to identify hazardous areas on the models in the process. [6]

The first prototypes allow the factory to correctly design a wax tree. This step is extremely important for the implementation of serial production and the efficiency of manufacturing processes.

If it is necessary to make a higher number of models before the milled mold for the wax injection molding machine is prepared, it is possible to use 3D printed models as a temporary solution.

In modern competitive environment between factories, it is very important for the factory to provide the customer with a representative casting as quickly as possible. At these key points, it is possible to make the first test sample in a matter of days. [6] [8]

\subsection{Requirements for models made by additive technology}

\subsubsection{Achieving print accuracy}

Most businesses require a model surface accuracy within a tolerance of $-+0.1 \mathrm{~mm}$. This point is often problematic to meet with some types of RP production.

\subsubsection{Model finishing}

All currently available RP model production facilities create their parts by layering the material. This process causes the material and grooves to lay down, especially on sloping surfaces. These structures are unacceptable and therefore sufficient quality production equipment or model finishing must be used before being included in the casting process. [4]

\subsubsection{Residual ash}

The purity of the wax burn out is one of the key factors in the materials used in RP technologies. The purity of the shell is essential for the correct casting of the products and can be a significant problem with poorly selected materials for prototype series or small series production. [1] 


\subsubsection{Robustness of the material}

When handling wax, the risk of damage to the model is not to be underestimated when transported or stored in an environment with elevated temperature. Some materials allow more robust handling of models that are not as susceptible to temperature or humidity changes as wax material.

\subsubsection{Foundry defects}

Casting defects can occur due to poor model surface. Examples of these defects may be porosity or surface defects in the casting. The occurrence of such damage is mainly associated with poorly bound layers of RP models. These defects can be invisible to the naked eye up to the point of casting itself. [1] [4]

\subsubsection{Compatibility with existing technologies}

Some materials and processes require changes in the company's production process. The fewer such modifications are necessary, the more efficiently it is possible to implement models produced using RP technology into the common practice of foundries.

\subsection{POLYCASTTM}

Polycast is a specially developed type of filament for FDM (Fused Deposit Modeling) printers from Polymaker s.r.o. . This material can be used with any printer as a regular filament with the correct printing conditions. This fact greatly expands the field of application as well as the availability of POLYCASTTM material. Many large companies as well as smaller companies can experiment with this type of filament with minimal investment in printing technology, unlike other materials, whether directly wax or substitute. [10] [11]

POLYCAST $^{\mathrm{TM}}$ material is also well supported by a range of equipment designed specifically for the production and finishing of prints designed for precision casting technology. During the printing itself, it is extremely important to maintain a constant moisture content of the material, as it is prone to wetting, which results in a deterioration of the printing properties. PolyBox ${ }^{\mathrm{TM}}$ was made for this purpose specifically. [10]

Polymaker also responded to the need for finishing processes for models made using additive technology. The parts produced in this way have an imperfect surface which would be fully reflected on the finished casting. For this reason, it is necessary to machine each print so that the surface of the print is as smooth as possible. The Polysher device provides aerosol application of isopropyl alcohol (IPA). The material is etched and smoothed under the influence of this substance. This process is by Polymaker s.r.o. designated as Layer-Free ${ }^{\mathrm{TM}}$ technology. Figure 2 illustrates the change this process has to parts. [11]

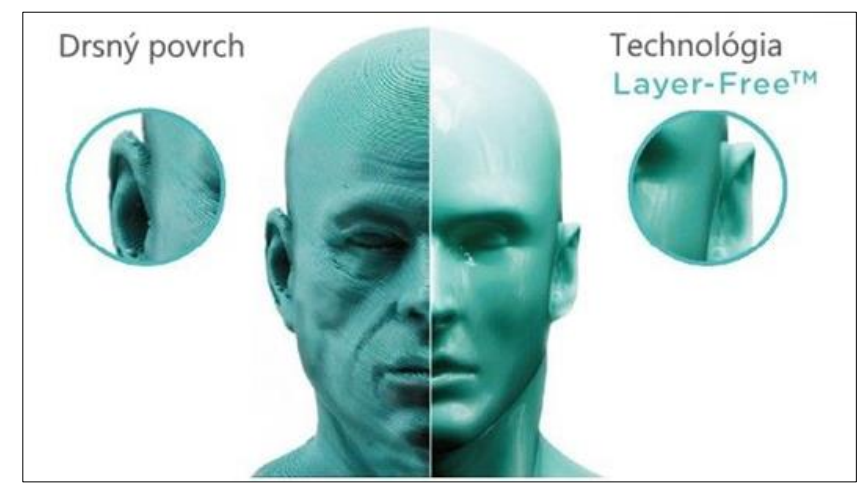

Figure 2 Layer-Free ${ }^{\mathrm{TM}}$ technology [11]

For investment casting technology, melting and burn out of wax trees is a key point in production, as already mentioned, many 3D printing materials cause considerable problems at this point. POLYCAST ${ }^{\mathrm{TM}}$ material not only has full compatibility with wax, but also shrinks during heating, which does not endanger the ceramic shell of the mold. Ash after burn out process of materials are also important. After many filaments, ash or even unburned residues remain with the shell, which subsequently destroys the castings and increases the number of defective pieces in the series. POLYCAST ${ }^{\mathrm{TM}}$ material has Ash-Free ${ }^{\mathrm{TM}}$ technology implemented. as can be seen in Figure 3, compared to filaments without net firing support where up to $0.5 \%$ of the original material trapped on the shell walls remains in the mold, the POLYCAST $^{\mathrm{TM}}$ can be burned up to a residual ash content of $0.003 \%$. [11] [12] 


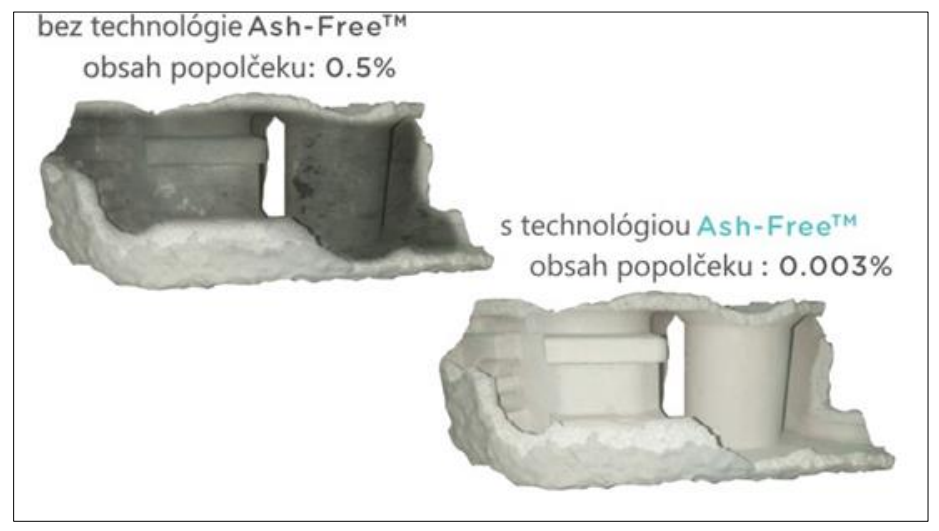

Figure 3 Ash-Free ${ }^{\mathrm{TM}}$ technology [11]

Despite its undeniable advantages, the POLYCAST ${ }^{\mathrm{TM}}$ material also has some drawbacks compared to classic wax. After the models are burned out, no adhering material remains on the wall of the ceramic shell, but the correct processing of the shells made of POLYCAST ${ }^{\mathrm{TM}}$ parts involves rinsing and drying of the ceramic shell, as also stated by the manufacturer (source). This step is necessary and if the mold is cast without rinsing, the resulting casting may be damaged. For smaller companies, such care does not represent a significant increase in load at the cost of excellent models and speed of shell production, but for large-scale production, it is not possible to implement rinsing in normal operation without significant changes and additional equipment and personnel costs. [11] [12]

In the next section, the characteristics of the POLYCASTTM filament will be summarized. Table 1 shows the characteristics related to the printing settings of the material, its mechanical properties as well as its thermal properties. It should be noted that the ideal properties of the material, especially for its printing, are achieved when using the PolyBox ${ }^{\mathrm{TM}}$ drying device. The values given in Table 1 therefore correspond to the data for the filament thus treated. [11] [12]

Table 1 Material properties of POLYCASTTM [11] [12]

\begin{tabular}{|c|c|}
\hline Material & POLYCASTTM $^{\mathrm{T}}$ \\
\hline Price & $54,95 € / 750 \mathrm{~g}$ \\
\hline \multicolumn{2}{|l|}{ Print settings } \\
\hline Nozzle temperature & $190^{\circ} \mathrm{C}-220^{\circ} \mathrm{C}$ \\
\hline Printing speed & $40 \mathrm{~mm} / \mathrm{s}-60 \mathrm{~mm} / \mathrm{s}$ \\
\hline Bed Temperature & $25^{\circ} \mathrm{C}-70^{\circ} \mathrm{C}$ \\
\hline Bed Surface & Glass with glue / smooth pad \\
\hline \multicolumn{2}{|l|}{ Mechanical properties } \\
\hline Tensile Strength (MPa) & $60.2 \pm 1.6$ \\
\hline Bending Strength (MPa) & $37.5 \pm 1.7$ \\
\hline Youngov modulus (MPa) & $174560.2 \pm 151$ \\
\hline Charpy Impact Strength $(\mathrm{kJ} / \mathrm{m} 2)$ & $9.6 \pm 0.9$ \\
\hline \multicolumn{2}{|l|}{ Thermal properties } \\
\hline Vicat Softening Temperature: & $67^{\circ} \stackrel{\mathrm{C}}{ }$ \\
\hline Decomposition Temperature: & $260^{\circ} \mathrm{C}$ \\
\hline \multicolumn{2}{|l|}{ Notes } \\
\hline Residue ash & $0,003 \%$ \\
\hline Recommended Support Materials: & PolyDissolve ${ }^{\mathrm{TM}} \mathrm{S} 1$ \\
\hline
\end{tabular}

POLYCAST ${ }^{\mathrm{TM}}$ material is generally a very well-designed filament for FDM printers which allows the customer to prototype parts very quickly and efficiently when properly operated. Its great advantage is the strength of the filament, 
which allows trouble-free printing on any equipment, but for ideal use, it is recommended to procure equipment supplied by the manufacturer for drying the material as well as processing the prints to achieve maximum casting quality.

\subsection{MOLDLAY}

This material is a plastic filament for FDM printers that directly mimics the properties of wax. The advantage of the MOLDLAY filament is the fact that it can be applied directly to the production of a model for investment casting or as a classic filament to produce durable models. It is chemically and dimensionally very stable at room temperature, which improves the possibilities of transport and storage of printed parts. [13]

The filament of the MOLDLAY material itself resembles wax in its texture and properties, unlike other materials, which are closer to classic PLA filaments. After extrusion, the parts can be heat or chemically treated to level the surface. However, this process requires considerable attention and a proven procedure for the application of heat or chemicals recommended by the manufacturer to safely obtain a properly machined surface.

Because the material is very malleable even after the part has been extruded, like wax, it is very susceptible to damage during the machining step of model preparation. One of the other advantages that should be mentioned is the ductility of the material preserved after printing. At this point, it is possible to intervene in the finished model for possible additional marking or material removal. These additional interventions are very simple and eliminate the need to produce new models to implement minimal changes. Material repairs are also very simple, MOLDLAY is fully compatible with modeling waxes. Any unevenness or printing error is not a reason to exclude the model, as it can be corrected by modeling with wax before connecting to the inlet tree. Figure 4 shows a representative part made of MOLDLAY material. [13] [14]

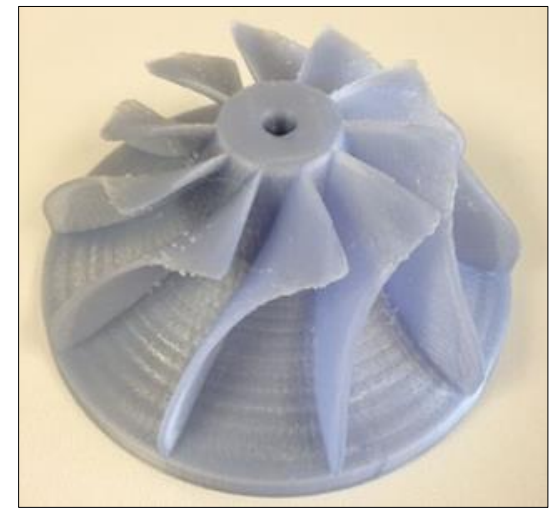

Figure 4 MOLDLAY model [14]

The temperature at which the model burns out of the mold is also very important for the incorporation of MOLDLAY material into the production of precision castings, which is between 270 and $280^{\circ} \mathrm{C}$ for this filament. For comparison, the most common apparatus for melting ceramic shells is a boilerklave, the operating temperature of which ranges from 150 to $180^{\circ} \mathrm{C}$.

MOLDLAY filament therefore requires a higher temperature for complete shell melting, for this process gas furnaces with afterburning system are recommended, which may limit the usability for large series operations that rely on their usual shell melting system. Another problem with the material is the complex setting and tuning of the printing parameters for the correct fabrication of the part. The nature of the material, which is very similar to wax, greatly complicates printing and it is necessary to perform several experiments for a particular printing machine as well as the model itself for its correct configuration and to achieve the best possible print result. [13]

Technical data for MOLDLAY material are shown in Table 2 as an overview of printing, mechanical and thermal properties of the filament. [13] 
Table 2 Material properties of MOLDLAY

\begin{tabular}{|l|l|}
\hline Material & Moldlay \\
\hline Price & $71,94 € / 750 \mathrm{~g}$ \\
\hline Print settings & $175-180^{\circ} \mathrm{C}$ \\
\hline Nozzle temperature & -none recommended- \\
\hline Printing speed & $<40^{\circ} \mathrm{C}$ \\
\hline Bed Temperature & smooth pad with glue \\
\hline Bed Surface & not specified \\
\hline Mechanical properties & not specified \\
\hline Tensile Strength (MPa) & \multicolumn{2}{|l}{} \\
\hline Bending Strength (MPa) & $170^{\circ} \mathrm{C}$ \\
\hline Thermal properties &
\end{tabular}

\subsection{PRINT2CAST wax filament}

This wax filament from MachinableWax represents, like the MOLDLAY material, an effort to create a filament that would directly copy the behavior of the wax. Unlike harder filaments such as POLYCAST ${ }^{\mathrm{TM}}$. This filament has good extrusion strength but is also easy to work with, it also possesses excellent burnout without residual ash, Print2Cast wax filament is directly formed as an artificial wax that can be printed on 3D printing devices. [15]

MachinableWax manufactures waxes for companies and artists in many specifications. Their range is characterized by high-quality bag blocks that can be machined either manually or by machine to achieve the desired shape. They bring all these features to 3D printing as a Print2Cast filament. The material has good workability and toughness for handling after the model. After production, it is also possible to machine the prints from the 3D printer as illustrated in Figure 5, as well as to interfere with the model with hand tools. Due to its waxy nature, the model is still flexible, and it is possible to modify shapes on parts much easier than with classic plastic filaments or harder filaments for precision casting such as POLYCAST ${ }^{\mathrm{TM}}$. [15]

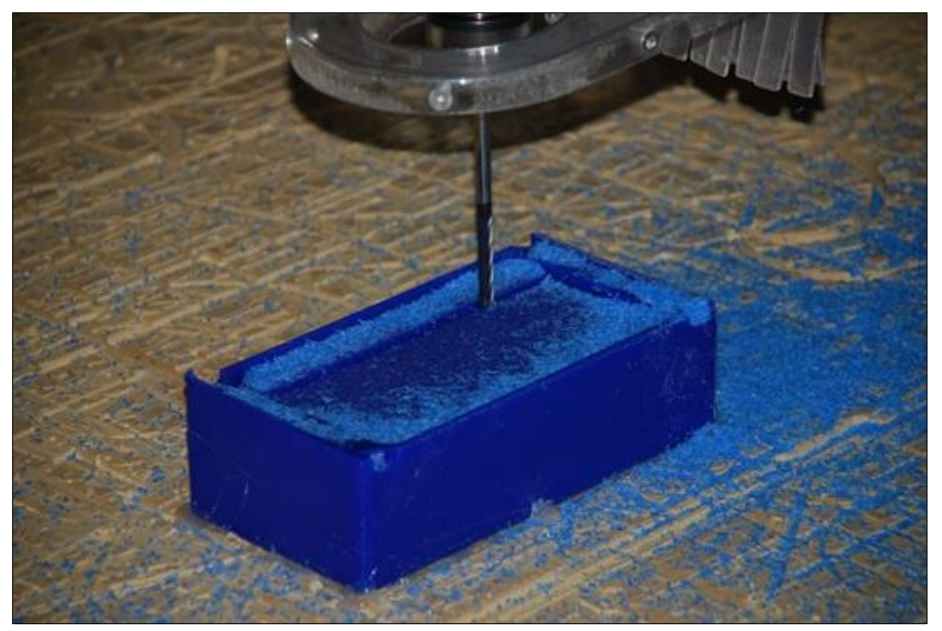

Figure 5 Processing of PRINT2CAST WAX FILAMENT block [16]

When making a model using Print2Cast from MachinableWax, it is also possible to process the model chemically or thermally, but this additional process requires a tested procedure, tuned for the part, as there is a risk of damage to the product. Another advantage of the filament is its compatibility with wax in the process of investment casting, the 
material is fully compatible with the wax inlet, and it is possible to combine the part with modeling wax to add or change shapes. [15]

The issue of using the Print2Cas material is mainly its demanding printing, similarly to the MOLDLAY material. The material manufacturer MachinableWax provides a recommendation to modify the print head for proper material processing, as well as a list of printing devices that can process the filament without problems. Another important step in production is more demanding print preparation, where it is necessary to pay attention to the preparation of the printing pad by proper smoothing of the surface and applying a sufficient amount of fixing agent and ensure constant conditions throughout the printing process. As with the MOLDLAY material, mild problems were encountered when transporting models. Technical similarity to wax, which is very important in the casting process, is reason they are also prone to thermal damage as well as manual failure of the model due to improper handling and transport of parts. The great advantage of this filament is also its melting temperature, which is at the level of $116^{\circ} \mathrm{C}$, which allows the melting of models directly in the boilerklave type machines. [15]

The technical data for Machinable wax Print2Cast are summarized in Table 3.

Table 3 PRINT2CAST WAX FILAMENT material properties [15]

\begin{tabular}{|l|l|}
\hline Material & Print2Cast \\
\hline Price & $32,18 € / 750 \mathrm{~g}$ \\
\hline Print settings & $140^{\circ} \mathrm{C}-150^{\circ} \mathrm{C}$ \\
\hline Nozzle temperature & $20 \mathrm{až} 70 \mathrm{~mm} / \mathrm{s}$ \\
\hline Printing speed & $80^{\circ}-90^{\circ} \mathrm{C}$ \\
\hline Bed temperature & $\mathrm{smooth} \mathrm{pad} \mathrm{with} \mathrm{glue}$ \\
\hline Bed surface & \\
\hline Mechanical properties & 53 \\
\hline Hardness (shore "d" scale) & $0.92949 \mathrm{~g} / \mathrm{cm}^{3}$ \\
\hline Density & $5 \%$ \\
\hline Volumetric shrinkage & $116^{\circ} \mathrm{C}$ \\
\hline Thermal properties & $0,006 \%$ \\
\hline Vicat softening temperature: & \multicolumn{2}{|l}{} \\
\hline Notes & \\
\hline Residue ash & \\
\hline
\end{tabular}

Overall, the Print2Cast material is very suitable for artistic needs, but it is also an excellent material for prototype production for small-batch precision casting companies. The benefit of the material for large-scale production is mainly based on the fact that, according to the manufacturer, it should be possible to melt models without further processes directly in the boilerklave. In this way, the prototype parts could be incorporated directly into the normal process without the need to change or add steps to the production process. When implementing this material, it is necessary to take into account the need to purchase the right equipment, as well as being able to work properly with softer types of filaments.

\section{Wax resin filaments}

Wax-like filaments are also produced for 3D printers using photopolymer resin reinforcement technology. These printers, called SLAs, produce highly detailed and smooth prints that outperform FDM printers with filament printing material in terms of accuracy and surface quality.

Despite their advantages in terms of models, printers are limited in workspace. The price of the equipment is growing very fast with a work surface that is significantly smaller than with cheaper FDM printers. The result is a significant 
limitation on the volume of the resulting model that the printer can produce, as well as higher input costs for the foundry equipment itself, which would be interested in implementing 3D printing technology into the production process. We should also not forget the prices of the cartridge, which also exceeds the prices of filament cartridges for FDM printers.

Due to these specific advantages and problems, rezin 3D printers are most often used in the jewelry industry, where a small volume of the working vessel is not a big problem, as well as the price of equipment and resin compared to the price of the final product.

\subsection{Liqcreate wax castable}

Wax-based resin is suitable for DLP, LCD and laser 3D printers. The material is suitable for the production of goldsmith's products, dental prostheses or aids as well as for the manufacture of industrial parts using the method of investment casting. [17]

Liqcreate wax castable is a resin cartridge based on a blue type of wax that has excellent processability on 3D printers. Prints from this material capture all the details for flawless fabrication of the final part. It is also possible to print complex shapes as shown in Figure 6. [17]

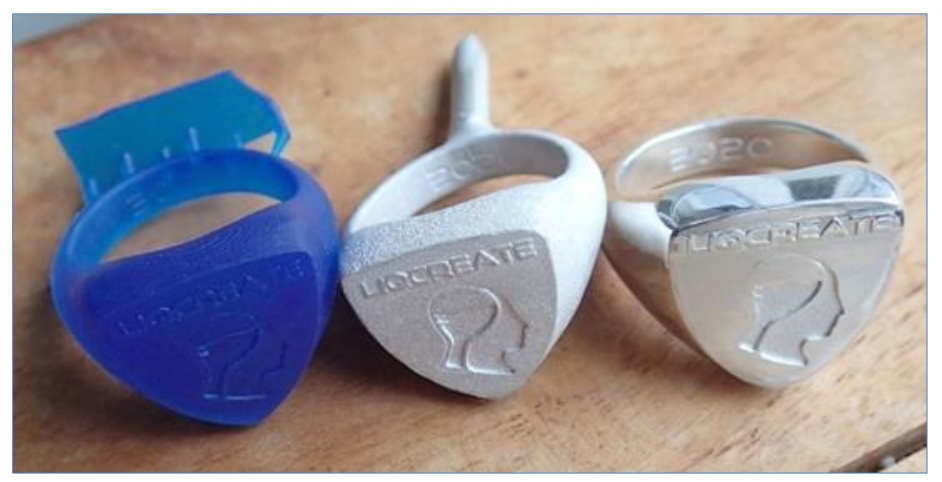

Figure 6 Liqcreate wax castable casting process [17]

This wax-like resin also offers a very good surface smoothness with the possibility of polishing as well as a minimum of residual ash after firing the shells. [17]

The technical data for Liqcreate wax castable from Liqcreate are summarized in Table 4.

Table 4 Material properties Liqcreate wax castable [17]

\begin{tabular}{|l|c|}
\hline Material & Liqcreate wax castable \\
\hline Price & $90,90 € / 1 \mathrm{~kg}$ \\
\hline Fluid properties & Blue fluid \\
\hline Appearance & $700 \mathrm{cps}$ at $25^{\circ} \mathrm{C}$ \\
\hline Viscosity & $1.18 \mathrm{~g} / \mathrm{cm}^{3}$ \\
\hline Density & 77 \\
\hline Mechanical properties of the polymer \\
\hline Hardness (shore "d" scale) & $33 \mathrm{Mpa}$ \\
\hline Flexural strength & $0,28 \%$ \\
\hline Water absorption & Exact value not specified \\
\hline Notes &
\end{tabular}


The Liqcreate wax castable material is generally very suitable to produce jewelry and detailed parts of smaller dimensions. It offers high surface quality, the possibility of precise printing as well as full compatibility with the wax tree. There is also a wide range of compatible printing devices. One of the disadvantages of the material is its relatively high purchase price and the need for a higher investment in the resin printer machine.

\subsection{Wax castable resin}

The Wax Castable Resin 3D printer cartridge from PowerResins.com also mimics the mechanical and physical properties of wax. As with the previous materials, this one is also used primarily for goldsmithing. [18]

According to the information provided by the manufacturer, the material should have a very clean burn-out which should be close to the purity of the conventional modeling wax used in the normal precision casting process, which can be achieved by a normal melting cycle. Models created using Wax Castable Resin also have excellent surface accuracy as well as the ability to make precise and highly complicated shapes. The example is provided in Figure 7. [18]

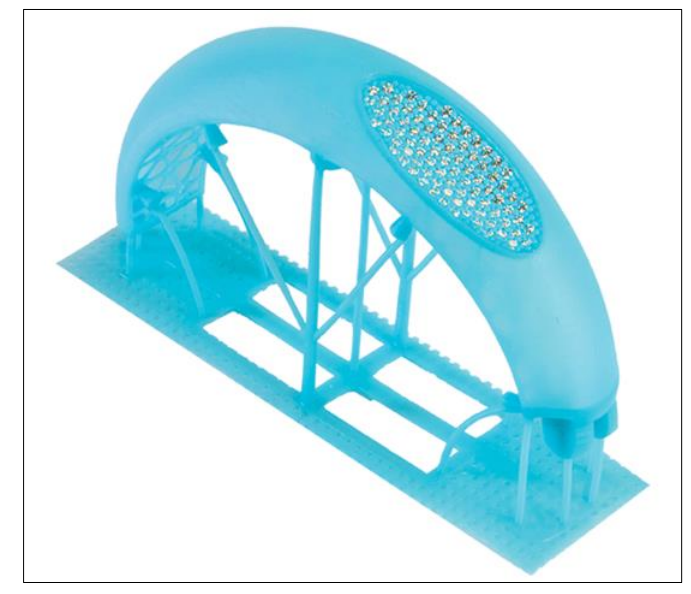

Figure 7 Model made of Wax Castable Resin material [18]

This special resin can be used on DLP type printing devices or LED curing 3D printers. [18]

PowerResins.com WAX Castable Resin specifications are shown in Table 5.

Table 5 Properties of WAX Castable Resin [18]

\begin{tabular}{|l|c|}
\hline Material & WAX Castable Resin \\
\hline Price & $303 € / 1 \mathrm{~kg}$ \\
\hline Fluid properties & Pale blue liquid \\
\hline Appearance & $730-760 \mathrm{mPa}$.s at $23^{\circ} \mathrm{C}$ \\
\hline Viscosity & $1.08 \mathrm{~g} / \mathrm{cm}^{3}$ at $23^{\circ} \mathrm{C}$ \\
\hline Density & $12,2 \mathrm{Mpa}$ \\
\hline Mechanical properties of the polymer \\
\hline Hardness (Shore "D" Scale) & $10,4 \mathrm{Mpa}$ \\
\hline Flexural strength & 55,6 \\
\hline Tensile strength & Exact value not specified \\
\hline Notes
\end{tabular}


WAX Castable Resin also recommends performing a three-step post-process adjustment of the printouts to achieve the best possible casting results:

\subsection{Washing}

- $\quad$ After printing, we rinse the model with the printing pad in ethyl alcohol ( $>\% 90$ ) or isopropyl alcohol ( $>\% 90)$

- It is necessary to cover the model evenly with alcohol

- $\quad$ Excessive alcohol application can lead to loss of detail on models

\subsection{Drying}

- It is recommended to use an air compressor to dry the model

- If there are still traces of excess resin on the models, the process of soaking in alcohol must be repeated

\subsection{Separation of printing bed and storage}

- $\quad$ Separate the models from the printing plate

- WAX Castable Resin is stored in a dark, dry room at room temperatures ranging from $20^{\circ} \mathrm{C}$ to $24^{\circ} \mathrm{C}$

The Wax Castable Resin material from PowerResins.com is a high-quality filament for resin 3D printers, enabling quality and accurate printing. It has very similar properties to wax, which allows excellent implementation in the production process of foundries. The manufacturer also states an almost flawless burn-up without residual ash and good adhesion of the material to ordinary wax.[18]

The disadvantage of the Wax Castable Resin material is its considerably high price, which raises the costs of producing prototype models, as well as the need to finish the prints post-process. On the other hand, we are thus able to achieve a higher quality of castings, so this option provided by the manufacturer is not necessarily negative.

\section{Conclusion}

The selection of a suitable material to produce models by the method of rapid prototyping in the field of investment casting depends very much on the customer's requirements as well as the possibilities of the foundry. Materials such as POLYCAST $^{\mathrm{TM}}$ are affordable and technologically very good, but they need post-print adjustments as well as special operations with ceramic shells. On the other hand, materials such as MOLDLAY or Print2Cast can be processed more easily but printing the model itself is often problematic and requires a special configuration of the printing device for each model.

Resin-based materials are an excellent alternative for foundries in the field of prototypes or small series castings. The surface quality of the model is excellent, and the physical properties allow the models to be put directly into production without further steps. However, a significant disadvantage is the price of the printing equipment as well as the prices of the wax resins themselves, which would require a high initial investment by the company.

\section{Compliance with ethical standards}

\section{Acknowledgments}

The paper is a part of the research done within the project APVV-18-0527 "Development and optimization of additive manufacturing technology and design of device for production of components with optimized strength and production costs" funded by the Slovak Research and Development Agency.

\section{Disclosure of conflict of interest}

There is no conflict of interest.

\section{References}

[1] CAMPBELL, John. Castings. 2nd ed. Oxford: Elsevier Butterworth-Heinemann. 2003; 8: 337.

[2] A short introduction to investment casting wax. Blayson [online]. United Kingdom [cit. 2021-11-16]. 
[3] A short introduction to wax pattern production and troubleshooting. Blayson [online]. United Kingdom [cit. 2021-11-16].

[4] BEELEY, Peter a Robert SMART. Investment Casting. 1 ed. London: The Institute of Materials. $1995 ; 486$.

[5] Investment Casting Process Steps (Lost Wax). American Casting Company [online]. USA [cit. 2021-11-16].

[6] Prakash, Chander, Sunpreet Singh, Harishankar Kopperi, Seeram Ramakrihna A S. Mohan. Comparative job production based life cycle assessment of conventional and additive manufacturing assisted investment casting of aluminium: A case study. Journal of cleaner production [online]. Elsevier Ltd. 2021; 289: 125164.

[7] Cheah Cm, Ck Chua, Cw Lee, C Feng A K Totong. Rapid prototyping and tooling techniques: a review of applications for rapid investment casting. International journal of advanced manufacturing technology [online]. Berlin/Heidelberg: Springer-Verlag. 2005; 25(3): 308-320.

[8] Badanova, Nazym, Asma Perveen A Didier Talamona. Concise review on Pattern making process in Rapid Investment Casting: Technology, Materials \& Numerical modelling aspect. Advances in materials and processing technologies (Abingdon, England) [online]. Taylor \& Francis. 1-13.

[9] Ševčík, Lukáš. Technologie vytavitelného modelu v současnosti. Brno: Vysoké učení technické v Brně. Fakulta strojního inženýrství. 2015.

[10] Polymaker [online]. [cit. 2021-11-16].

[11] POLYCAST FILAMENT NATURAL 1,75MM POLYMAKER 750G. MATERIALPRO 3D [online]. [cit. 2021-05-15].

[12] POLYCAST ${ }^{\mathrm{Tм}}$. 3D Printing Solutions [online]. [cit. 2021-05-15].

[13] MOLDLAY Filament - $1.75 \mathrm{~mm}(0.75 \mathrm{~kg})$. MatterHackers.

[14] MOLDLAY Filament - 1.75mm. Filaments.ca

[15] Wax Filament. MACHINABLEWAX.COM [online].

[16] Wax Machining of Core and Cavity Molds - ShopBot Desktop. In: The Invention Factory [online].

[17] Liqcreate Resin for SLA, DLP \& MSLA 3D Printers - Wax Castable (1kg). MatterHackers [online].

[18] WAX Castable Resin. Power resins [online]. 